\title{
Using mobile phone telemetry to investigate the haul-out behaviour of harbour seals Phoca vitulina vitulina
}

\author{
M. A. Cronin ${ }^{1, *}$, A. F. Zuur ${ }^{2}$, E. Rogan ${ }^{3}$, B. J. McConnell ${ }^{4}$ \\ ${ }^{1}$ Coastal \& Marine Resources Centre, ERI, University College Cork, Naval Base, Haulbowline, Cobh, Co. Cork, Ireland \\ ${ }^{2}$ Highland Statistics Ltd., 6 Laverock Road, Newburgh AB41 6FN, UK \\ ${ }^{3}$ Department of Zoology, Ecology \& Plant Science, University College Cork, The Enterprise Centre, Distillery Fields, \\ North Mall, Co. Cork, Ireland \\ ${ }^{4}$ Sea Mammal Research Unit, Gatty Marine Laboratory, University of St. Andrews, Fife KY16 8LB, UK
}

\begin{abstract}
Information on the haul-out behaviour of pinnipeds is essential for increasing the accuracy of population estimates necessary for the effective conservation of protected species, as well as improving survey design. The haul-out behaviour of 10 harbour seals Phoca vitulina L. in southwest Ireland was examined using a novel telemetry system based on global systems for mobile communications technology. The data on the haul-out patterns of tagged individuals were examined using generalised additive modelling to determine potential factors of influence, such as the tide, the time of day and the time of year. The behaviour varied among seals, with time ashore reaching a maximum during post-moult in October and decreasing to a minimum in February. A strong tidal influence on haul-out behaviour was evident. Tagged seals hauled out more frequently at low tide. There was variation between individuals in the influence of time of day on haul-out behaviour. A cyclic pattern with lunar periodicity was evident in seals tagged in October, and the pattern varied between tidal periods. There was an overall large variation in patterns of behaviour over the tagging period, both between individuals and between tidal periods for each individual. This cautions against making inferences on the haul-out behaviour of the 'population' based on the behaviour of a small number of tagged individuals. The present study provides detailed information, heretofore unavailable, on the haul-out behaviour of individual harbour seals and on the behaviour of the species in Ireland, and it has important implications for population assessment for conservation purposes across the species' entire geographical range.
\end{abstract}

KEY WORDS: Generalised additive modelling $\cdot$ Haul-out behaviour $\cdot$ Lunar influence $\cdot$ Telemetry Resale or republication not permitted without written consent of the publisher

\section{INTRODUCTION}

The harbour seal Phoca vitulina L. is a widely distributed pinniped, inhabiting cold-temperate and temperate waters in the North Atlantic and North Pacific (Bigg 1981). In Europe the harbour seal is listed as an Annex II species under the European Community's Habitats Directive (92/43/EEC), i.e. a protected species whose conservation requires the designation of special areas of conservation. Accurate assessment of population size, terrestrial and aquatic distribution and range is essential for the effective monitoring of the conservation status of the species. In some parts of the harbour seal's range, such information is lacking or incomplete. Recent efforts have addressed the shortfall in fundamental population data on the harbour seal in Ireland, including a national census to establish a minimum population estimate (Cronin et al. 2007) and local studies on year-round changes in the terrestrial distribution and abundance of harbour seals in southwest Ireland (Cronin 2007). Such efforts, whilst providing fundamental baseline information on population size 
and distribution, fall short at enabling us to understand the environmental forcing on haul-out behaviour.

Estimates of population size are primarily derived from counting the numbers of individuals ashore at haul-out sites. However, counts of seals at terrestrial sites can only be considered minimum population estimates, as a fraction of the population will be at sea and unavailable to count. Minimum population estimates of seals, as opposed to abundance estimates, although sufficient for investigating population trends, are inadequate for conservation objectives, for example, in assessing the impact of by-catch or directed takes or in determining the predation pressures on fish stocks by a seal population. Information on harbour seal haul-out behaviour has been used to derive a correction factor to account for the missing element of the population during counts and to obtain a true abundance estimate (Yochem et al. 1987, Thompson \& Harwood 1990, Thompson et al. 1997, Ries et al. 1998, Huber et al. 2001, Simpkins et al. 2003, Sharples 2005). Harbour seals haul-out behaviour has been shown to be influenced by extrinsic factors or 'covariates', including the time of year, time of day, tidal effects, disturbance and local weather (Stewart 1984, Yochem et al. 1987, Thompson et al. 1989, 1994, 1997, Thompson \& Harwood 1990, Thompson \& Miller 1990, Grellier et al. 1996, Reder et al. 2003). Understanding the effects of covariates on seal haul-out behaviour and therefore numbers at haul-out sites helps to enhance the design of surveys. Covariates can be factored into the statistical analyses to improve the accuracy of population and trend estimates (Frost et al. 1999, Adkison et al. 2003, Boveng et al. 2003, Small et al. 2003).

Prior to the present study there was a critical absence of information on the haul-out behaviour patterns of harbour seals in Ireland and the influence of environmental factors on this behaviour. Many studies have been undertaken addressing this point in other parts of the species' range; however, as it has been shown that behaviour varies temporally and spatially as does the relative importance of covariate effects on harbour seal haul-out behaviour, it is imperative to conduct such studies in Irish waters and not to assume that findings from other parts of the species' range are applicable locally. Our primary objectives, therefore, were to determine the activity patterns of harbour seals in southwestern Ireland and how these change over the annual cycle, to determine what factors affect the haulout behaviour of tagged seals and to explore the potential of deriving a correction factor to apply in haul-out counts of seals to estimate the total number of seals in the study area. The resulting information will contribute valuable information to the timing and planning of national harbour seal population assessment surveys and provide a methodology framework to potentially improve the accuracy of the population estimates for this protected species in Ireland.

Quantification of time spent ashore by marine vertebrates can prove to be a difficult, expensive and labour-intensive task. We tested a novel telemetry system based on global systems for mobile communications (GSM) technology (McConnell et al. 2004) to provide detailed information on the haul-out behaviour of harbour seals in SW Ireland. The GSM telemetry system proved to be an effective means of obtaining information on the haul-out activity of the seals and of providing crude movement information. This system is less labour intensive than VHF telemetry and provides an alternative means of data acquisition offering several advantages over satellite telemetry (Cronin \& McConnell 2008). The resulting haul-out dataset is statistically challenging to interpret, and we present here a sophisticated analysis involving generalised additive models (GAM) and mixed modelling to overcome this.

\section{MATERIALS AND METHODS}

Study site. Capture of harbour seals Phoca vitulina L. and deployment of tags was attempted in the Kenmare River, Co. Kerry, in SW Ireland, in October 2004 and April 2005. Seal capture was attempted only when the group size was $>10$ and the water depth was $<3 \mathrm{~m}$ (Fig. 1). Capture was attempted just once at each haulout site, to minimise disturbance to the seals.

Capturing and handling procedure and tag deployment. Tagging was staggered over the interval between moults (between early October and August), as

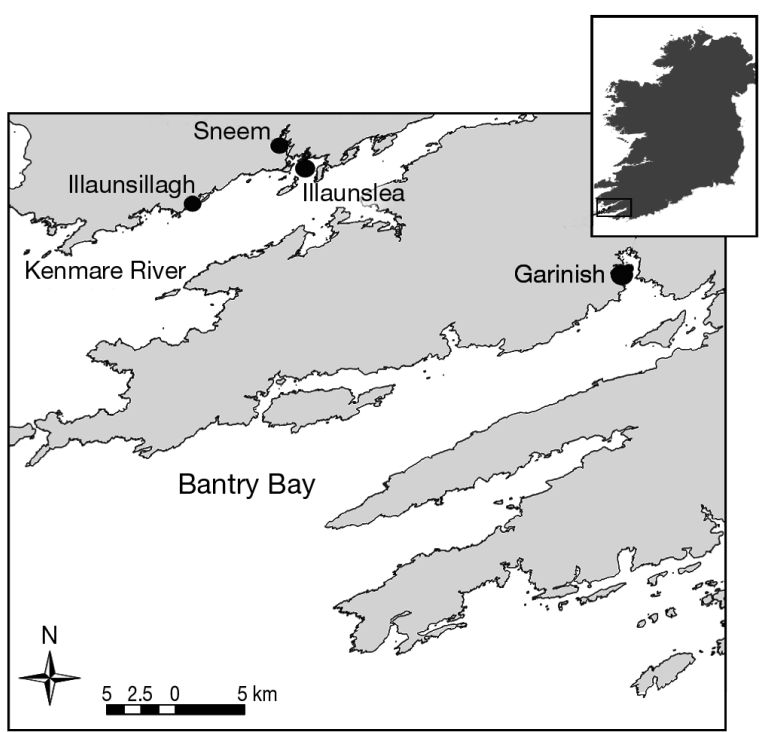

Fig. 1. Study area in southwestern Ireland, showing haul-out sites selected for seal Phoca vitulina capture and tag deployment 
the anticipated length of attachment was approximately 4 mo (R. Sharples, Sea Mammal Research Unit, pers. comm.). The technique employed for catching seals was similar to that described by Jeffries (1993). Two custom-made nets of the following dimensions were used: $60 \mathrm{~m}$ long $\times 3 \mathrm{~m}$ deep, 18 meshes on the gable end and 5.5 meshes per metre on the headline, an $8 \mathrm{~mm}$ float line with $70 \mathrm{~mm}$ long floats of $50 \mathrm{~mm}$ circumference spaced $270 \mathrm{~mm}$ apart and a lead-weighted sink line. Net deployment was carried out at speed from 2 rigid inflatable boats (RIBs), which approached the haul-out site from opposite sides and aimed to deploy the net around and as close to the haul-out site as possible. Seals entered into the water as soon as deployment commenced, and the nets formed a barrier in which they were entangled or trapped. Hoop nets, consisting of a $1 \mathrm{~m}$ diameter hoop made of $20 \mathrm{~mm}$ plastic hosing and a funnel net of $10 \mathrm{~mm}$ mesh attached, were used to assist in getting the captured animals into the boats. Captured seals were brought ashore, weighed suspended in the hoop net with a Salter scale (0 to $100 \mathrm{~kg}$ ) and anaesthetised using $0.05 \mathrm{ml}$ of Zoletil per $10 \mathrm{~kg}$ delivered intravenously. If intravenous administration of the anaesthetic proved difficult, an intra-muscular dose of $0.1 \mathrm{ml}$ of Zoletil per $10 \mathrm{~kg}$ was delivered instead to minimise stress to the animal. The entire handling and tagging procedure took no longer than $30 \mathrm{~min}$. Seal handling and tagging procedures were carried out under the National Parks \& Wildlife Service Licence Number C18/2005.

The tag was attached at the base of the skull and secured in place using fast-setting epoxy resin (Fedak et al. 1983). The positioning of the tag minimised drag effects when diving (Wilson et al. 1986). The tag weighed approximately $210 \mathrm{~g}$, less than the maximum recommended tag weight of $5 \%$ of animal mass (Cuthill 1991), and was shed when the seals underwent their annual moult. Previous telemetry studies using slightly larger tags reported no observable effects on the behaviour of tagged harbour seals (Thompson et al. 1989).

Tag operation. The tag is based on GSM mobile phone technology and was provided by the Sea Mammal Research Unit, St. Andrews University, Scotland. Details of the hardware and controlling software design can be found in McConnell et al. (2004). A wet/dry sensor in the tag is interrogated every $2.3 \mathrm{~s}$. A haul-out event is considered to start when the tag is continuously dry for $10 \mathrm{~min}$ and to end when it is continuously wet for $40 \mathrm{~s}$. The start and end times of the haul-out event, as well as a unique incremental number, are appended to a 160-character-long buffer. When the buffer is full, a short message service (SMS), also known as a text message, is created and stored in the SIM card. Every $4 \mathrm{~h}$ the tag 'wakes' from sleep mode, waits until it is dry and then attempts to send all unsent text messages.

Information relay and interpretation. Successful registration requires that the phone tag be within radio contact of a GSM radio cell. The maximum theoretical range is $35 \mathrm{~km}$, but it is often less than this as a result of obstruction of line of sight or radio interference (McConnell et al. 2004). It is not a prerequisite that the tagged animal remains in the GSM coastal corridor of coverage. However, tagged seals must return at some stage to this area in order to connect to the network and subsequently relay stored information.

The sequential number system allocated to haul-out events enabled the identification of lost haul-out records. This happened infrequently, when messages were dropped as a result of the tag failing to send a text message. It is important to identify these lost records, as failure to do so would overestimate at-sea duration. Haul-out 'status' of each tagged seal was determined hourly and was coded as: $0=$ seal in water, 1 = seal hauled out, or $-1=$ unknown.

Statistical modelling. The probability of a tagged seal hauling out was modelled as a function of explanatory variables (or covariates) using GAM. A GAM with a binomial distribution and logistic link function was used to model the response variable, i.e. haul-out status, as a function of the covariates tidal state, tidal level and time of day and month. Tidal data (tide level, time, speed, direction) for the tagging period at the study site were obtained from the tide prediction software Polpred V.2 (Proudman Oceanographic Laboratory). An hourly tidal 'state' value ( -6 to +6 ) and tidal level (m) were assigned to each hour on both the ebb and flood tides.

We defined $p_{s}$ as the probability that a particular seal is hauling out at time $s$ (expressed in hours). A binomial GAM was used to model $p_{s}$ as a function of the abovementioned covariates. Because the hauling-out status is a time series of ones (hauling out) and zeros (not hauling out), we used a model to identify the short-term variation from the long-term variation, such that:

$$
\begin{gathered}
\operatorname{Logit}\left(p_{s}\right)=\text { intercept }+ \text { short-term variation }+ \\
\text { long-term variation }
\end{gathered}
$$

Decomposing time series into short-term and longterm variation is quite common in the literature on time series analysis, see for example Harvey (1989), who developed methods of identifying daily cycles, monthly cycles and long-term trends. Other examples of methods of decomposing time series into seasonal and trend components can be found in Findley et al. (1998) and Makridakis et al. (1998), among many others. Within the context of GAM, Wood (2006) gives an example of how to identify daily variation and longterm trends, which we will follow here. 
With short-term variation, we mean daily changes in probabilities of hauling out, and these may be due to the tide, daylight, etc. Long-term variation is anything that is not short-term variation (and vice versa). A possible starting model is:

$$
\operatorname{Logit}\left(p_{s}\right)=\text { intercept }+\mathrm{f}(\text { tide })+\mathrm{f}(\text { hour })
$$

The term $\mathrm{f}$ (tide) is a smoother for the tidal height and models the short-term variation, whereas $\mathrm{f}$ (hour) is a smoother for hour (the time expressed in hours since the start of the experiment) and is the long-term trend. When fitting this model, we noticed that there were clear residual patterns, indicating that further extensions were needed. To model different hauling-out behaviours during the rising and falling parts of the 2 daily tides, the following categorical variable $T_{s}$ with 4 levels was created:

$$
T_{s}=\left\{\begin{array}{l}
1 \text { if observation } s \text { was during the rise of Tide } 1 \\
2 \text { if observation } s \text { was during the fall of Tide } 1 \\
3 \text { if observation } s \text { was during the rise of Tide } 2 \\
4 \text { if observation } s \text { was during the fall of Tide } 2
\end{array}\right.
$$

Interaction terms between the various tidal periods and smoothers were added to the model:

$$
\operatorname{Logit}\left(p_{s}\right)=\text { intercept }+\mathrm{f}(\text { tide }): T_{s}+\mathrm{f}(\text { hour }): T_{s}
$$

The notation $\mathrm{f}$ (tide): $T_{s}$ means that a smoother is applied to the data of each of the 4 periods, and this models seals behaving differently between these 4 periods. The some holds for the term $\mathrm{f}$ (hour): $T_{s i}$ it allows for different long-term behaviour during the 4 periods. Note that this is not an interaction term as we know it from linear regression, there is no need to include the main terms, and this avoids including both tide and $T_{s}$ as main terms (since these are collinear). We noted that the model in Eq. (2) still contained short-term (daily) residual patterns, and we therefore added an extra covariate to model daily variation:

$$
\begin{gathered}
\operatorname{Logit}\left(p_{s}\right)=\text { intercept }+\mathrm{f}(\text { tide }): T_{s}+ \\
\text { function (time of day) }+\mathrm{f}(\text { hour }): T_{s}+\text { month }_{s}
\end{gathered}
$$

The term function(time of day) can be implemented in different ways, e.g. with a smoothing function $\mathrm{f}$ (time of day), where time of day is expressed in hours from 0 to 23 , or with parametric sine and cosine terms using $\cos [2 \times \pi \times$ (time of day)/23] and $\sin [2 \times \pi \times$ (time of day)/23]. Both approaches gave similar results, and because the parametric sine and cosine terms took less computing time, we used these. The ecological interpretation of the time of day effect is behaviour other than that driven by the tides, e.g. daylight effects. For longer time series, an interaction term between month and time of day may be considered. This was not done here. We also included month in the long-term component (as a categorical variable) to discriminate between seasonal variation and trends.

The variables in the short- and long-term components are collinear, but, provided the time series are long enough, it is possible to discriminate between them. For very short time series (several days), hour and tide represent similar ecological information, and, in such cases, a long-term trend cannot be extracted. It is important to avoid collinear variables in the same term, e.g. tidal height and tidal state. We considered replacing $f$ (tide) by $f$ (tidal state), but initial analyses suggested use of the first covariate.

Cross-validation was applied to determine the optimal degrees of freedom for each smoother. Once the optimal degrees of freedom were determined Pearson and deviance residuals were plotted against the original explanatory variables. An assumption in the GAM is that the response data are independent, but, as the observations are made sequentially over time and the probability of hauling out at time $s$ is likely to depend on that at time $s-1$, the independence assumption is violated. In the presence of auto-correlation, p-values of smoothers can be seriously inflated (Ostrom 1990). Adding a correlation structure on the data, such as an auto-regressive error structure allowing for autocorrelation between the residuals of sequential hours, is a means of dealing with this inaccuracy (Wood 2006, Zuur et al. 2007, 2008). Generalised additive mixed modelling (GAMM) can be used when the data have a hierarchical or nested structure or include longitudinal or spatial elements. It was not possible to add the auto-regressive error structure in the GAMM function due to the long length of the time series of data that resulted from Tags 4, 5, 6, 7, 11 and 20 (see Table 1) and the lack of computer memory. Instead of incorporating a temporal correlation structure within the GAM model to get more reliable results, an alternative is to use the following bootstrap approach to calculate confidence intervals (Davidson \& Hinkley 1997).

Bootstrap variance estimation. The following steps were carried out: (1) the optimal GAM model (in terms of degrees of freedom and explanatory variables) was determined using ordinary model selection techniques (cross-validation and Akaike's information criterion), and fitted values and residuals were obtained; (2) the time series of the Pearson residuals was divided into blocks of $M$ days; (3) the residuals between blocks were permutated; (4) the permutated residuals were added to the fitted values in Step 1, and new data were obtained by rounding to 0 or $1 ;$ (5) a GAM was applied to the new data obtained in Step 4 using, for each smoother, the same degrees of freedom as in Step 1 ; (6) Steps 2 to 5 were 
Table 1. Phoca vitulina. Details of tag deployments and measurements of 10 harbour seals captured on the Kenmare River, Ireland, during 2004/2005

\begin{tabular}{|lllcccccc|}
\hline $\begin{array}{l}\text { Seal } \\
\text { tag no. }\end{array}$ & Date of tagging & Location & Sex & $\begin{array}{c}\text { Weight } \\
(\mathrm{kg})\end{array}$ & $\begin{array}{c}\text { Length } \\
(\mathrm{cm})\end{array}$ & $\begin{array}{c}\text { Girth } \\
(\mathrm{cm})\end{array}$ & $\begin{array}{c}\text { Duration of tagging } \\
(\mathrm{d})\end{array}$ \\
\hline 6 & & & & Male & 80 & 156 & 97 & 187 \\
$(\mathrm{~h})$ \\
5
\end{tabular}

repeated 1000 times; and (7) the 95\% quartile confidence intervals were obtained by sorting the 1000 bootstrapped values at each point and using observations 25 and 975.

In Step 2, the length of blocks was determined in a way to insure that the auto-correlation within a block was captured, but points beyond this length were not auto-correlated. Based on the estimated auto-correlation function, blocks of length $M=2$ or $M=3 \mathrm{~d}$ were used depending on the tag. The use of the same degrees of freedom as in Step 5 was motivated by computing time. Allowing the GAM algorithm to determine the optimal degrees of freedom in each bootstrap drastically increases computing time.

The importance of each covariate was assessed in a second bootstrap procedure, using a similar approach. Effects of a particular covariate were based on deviance of models that included and did not include the covariate. Difference in deviance was calculated for the original data and for each bootstrapped dataset. The data were permutated, the deviance was calculated, and the process was repeated 1000 times. The difference in deviances between the full model and the null model divided by 1001 represented the $\mathrm{p}$-value for the omitted explanatory variable. The entire bootstrapping approach was carried out for each covariate in turn. A more detailed description can be found in Algorithm 7.4 by Davidson \& Hinkley (1997).

All statistical analyses were carried out using R. The gam function from the mgcv package (Wood 2006) was used. The length of the data from Seals 2, 3, 9 and 10 was short enough to successfully apply the gamm function in the mgcv library of $\mathrm{R}$, with an auto-regressive error structure. A search for the optimal GAM model was carried out for Seals 4, 5, 6, 7, 11 and 20, and the data length was long enough to investigate the possibility of a long-term trend over the tagging period.

\section{RESULTS}

Ten harbour seals Phoca vitulina, 9 males and 1 female, were successfully captured at haul-out sites in the Kenmare River, Ireland, and tagged during October 2004 and April 2005 (Table 1). Four of the 10 seals tagged weighed $<60 \mathrm{~kg}$ and were considered to be juveniles (Härkönen \& Heide-Jorgensen 1990, Lydersen \& Kovacs 2005).

Individual tags transmitted over a period of 11 to $187 \mathrm{~d}$, with an average transmission duration of $75.5 \mathrm{~d}$, i.e. approximately 2.5 mo (Table 1). The amount of time spent ashore varied among individuals (Fig. 2). The average length of a haul-out event was $215 \mathrm{~min}$, and the longest and shortest haul-out events recorded were 1660 and $10 \mathrm{~min}$, respectively (10 min being the set time programmed in the tag to constitute a haul-out event). The majority (98\%) of haul-out events lasted $<12 \mathrm{~h}$. The longest recorded period spent at sea between haul-out events was $12607 \mathrm{~min}$, i.e. almost $9 \mathrm{~d}$. This individual (Seal 6) made multiple trips to sea of durations of $>4 \mathrm{~d}$. This behaviour of spending extended periods at sea was also evident in Seal 7. However, these long trips to sea represented $<1 \%$ of all trips made by tagged individuals. Most periods spent at sea ( $91 \%$ of trips) were $<24 \mathrm{~h}$, between daily haul-out events.

A distinct diurnal pattern in haul-out behaviour was evident in 6 of the tagged seals, spending more time ashore during early to mid-afternoon. Seal 5 appeared to have a preference for hauling out at night, while Seal 4 displayed a bimodal pattern, hauling out at night as well as in mid-afternoon (Fig. 2). The tagged seals spent a higher proportion of time ashore postmoult in October, decreasing over the winter months to a minimum in February, increasing until April and remaining relatively constant through the proceeding months until July. The mean proportion of time spent 

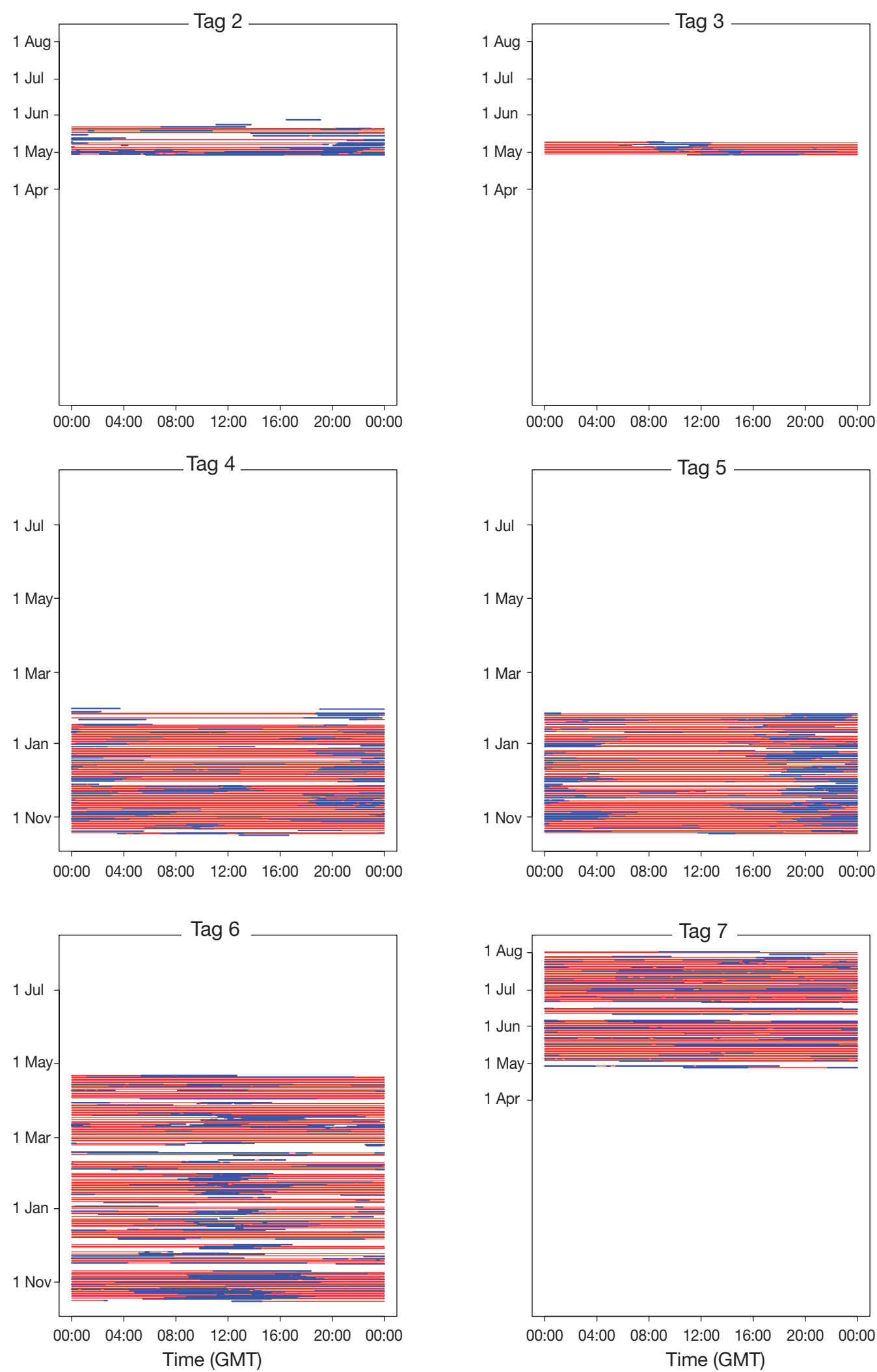

Fig. 2. Phoca vitulina. Haul-out records from tagged seals over the tagging period: Seals 2 to 7 (this page) and Seals $9,10,11$ and 20 (facing page). Blue lines: haul-out periods; red lines: periods when the seals were known to be not hauled out; white space: periods for which no information is available 

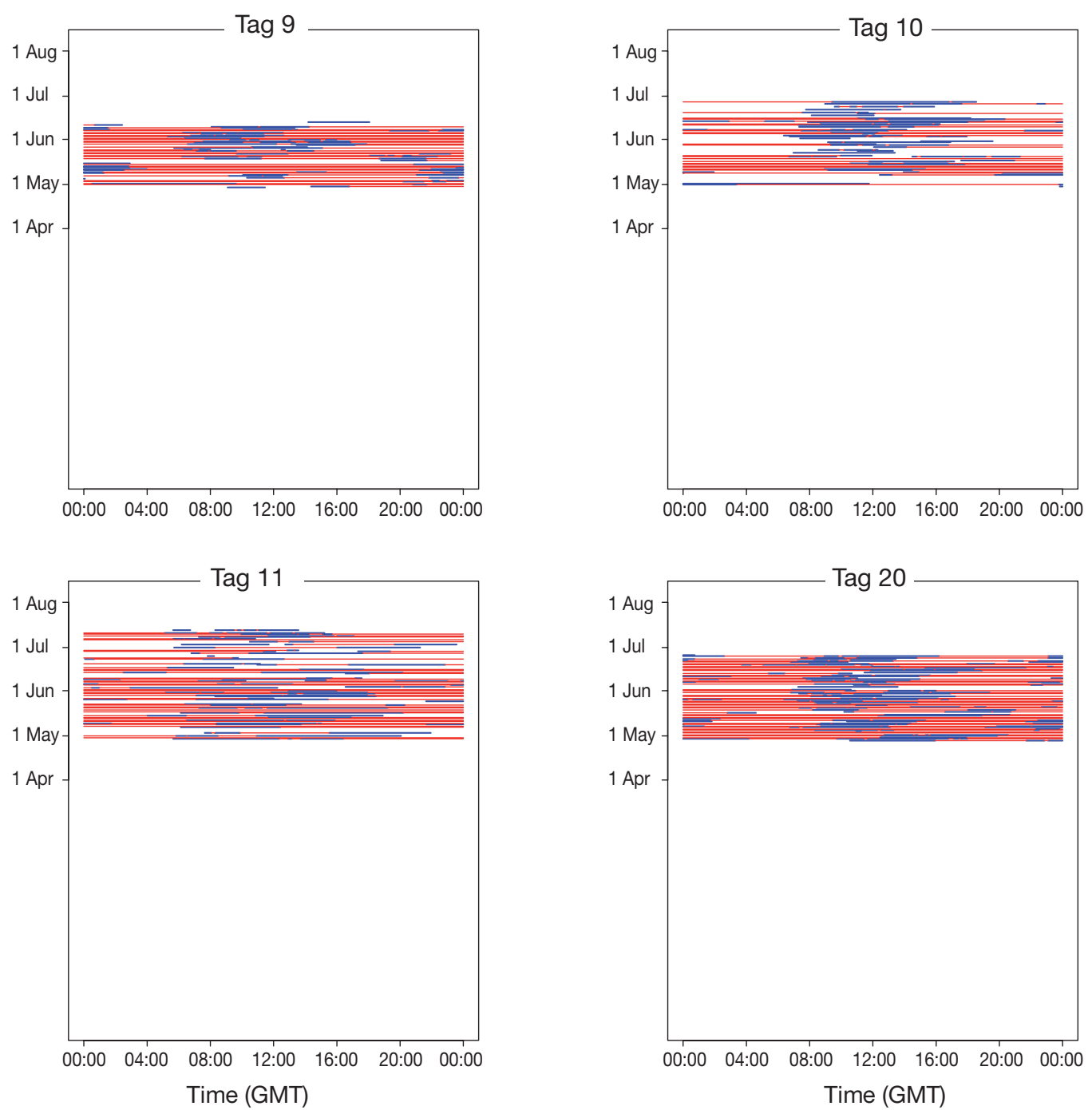

Fig. 2. (continued)

hauled out monthly ranged from 11 to $25 \%$ of the total time hauled out, with the minimum recorded in February and the maximum in October.

\section{Model outputs and validation}

An initial analysis was carried out to validate the modelling approach using the data from Seal 4, as it was one of the longest data records. The haul-out response of Seal 4 was modelled as described above, and the model is given by:

$$
\begin{aligned}
\operatorname{Logit}\left(p_{s}\right)= & \alpha+\mathrm{f}(\text { level }): T_{s}+\beta_{1} \sin \left(2 \pi \frac{\text { time of day }}{23}\right) \\
& +\beta_{2} \cos \left(2 \pi \frac{\text { time of day }}{23}\right)+\mathrm{f}(\text { hour }): T_{s}+\text { month }_{s}
\end{aligned}
$$

To simplify notation, the sine and cosine terms are labelled $Z_{1}$ and $Z_{2}$, respectively, such that:

$$
\begin{aligned}
\operatorname{Logit}\left(p_{s}\right)= & \alpha+\mathrm{f}(\text { level }): T_{s}+\beta_{1} Z_{1 s} \\
& +\beta_{2} Z_{2 s}+\mathrm{f}(\text { hour }): T_{s}+\text { month }_{s}
\end{aligned}
$$

The residuals obtained by this model still showed an auto-correlated structure, which came mainly from the Tidal Period 1 residuals. These results suggested that some processes that were in place for this timeframe were not explained well within the current model. Bootstrapping techniques were therefore applied to assess the significance of the smoothers.

Modelling the effects of time elapsed since deployment (hour) on the haul-out status of Seal 4 revealed various patterns: (1) a tidal pattern, i.e. a high probability of the seal being at sea during the first or second daily rising tide, but never during both; (2) a longer 
term tidal pattern, i.e. a higher probability of the seal being at sea on the first rising tide, for approximately the first $1500 \mathrm{~h}$ of the deployment, and on the second rising tide from then onwards; and (3) a pattern with lunar periodicity, i.e. the highest probability of being at sea just after the full moon each month, and on the first rising tide, and the highest probability of being hauled out also just after the full moon, but on the second rising tide (Fig. 3).

The optimal GAMs for data from Tags 5, 6, 7, 11 and 20 were variations on the optimal model for Tag 4 . The variations in the optimal model were associated with the nominal variable $T_{s}$. For some tags, a tidal level and/or hour smoother combining some or all of the 4 tidal periods constituted the best model. A long-term cyclic pattern similar to that seen for Seal 4 was evident in the other seals tagged over the autumn/winter months (Seals 5 and 6), and a possible lunar influence on the long-term haul-out behaviour is suggested by the highest probabilities of being either at sea or hauled out after a full moon. A similar pattern was apparent in Seal 20, but not in the other seals tagged over the spring/summer period. Overall there appears to be large variation in long-term haul-out patterns (1) between individuals, (2) between tidal periods for each individual and (3) over the tagging period.

The bootstrapped smoothing functions describing the partial effect of level on haul-out behaviour suggested that all tagged seals had a higher probability of hauling out at low tide, and the probability decreased with rising tide (e.g. Fig. 4 for Seal 4; not shown for other individuals). Bootstrapped data confirmed differences in the long-term patterns between autumn/winter and spring/summer.

There was a significant effect of tidal level on the short-term haul-out behaviour of all 10 seals; in the 6 seals with longer tagging records, this was true for all 4 tidal periods ( $p<0.001$ to $p<0.01$; Tables $2 \& 3$ ). A significant change in haul-out patterns over the tagging period and for particular tidal periods was evident in some seals. For instance, Seals 4 and 6 showed significant change in their haul-out pattern over the tagging period during tidal periods other than the second falling and rising tides, respectively. A significant change in the haul-out behaviour of tagged seals between months was apparent in only 1 of 5 seals
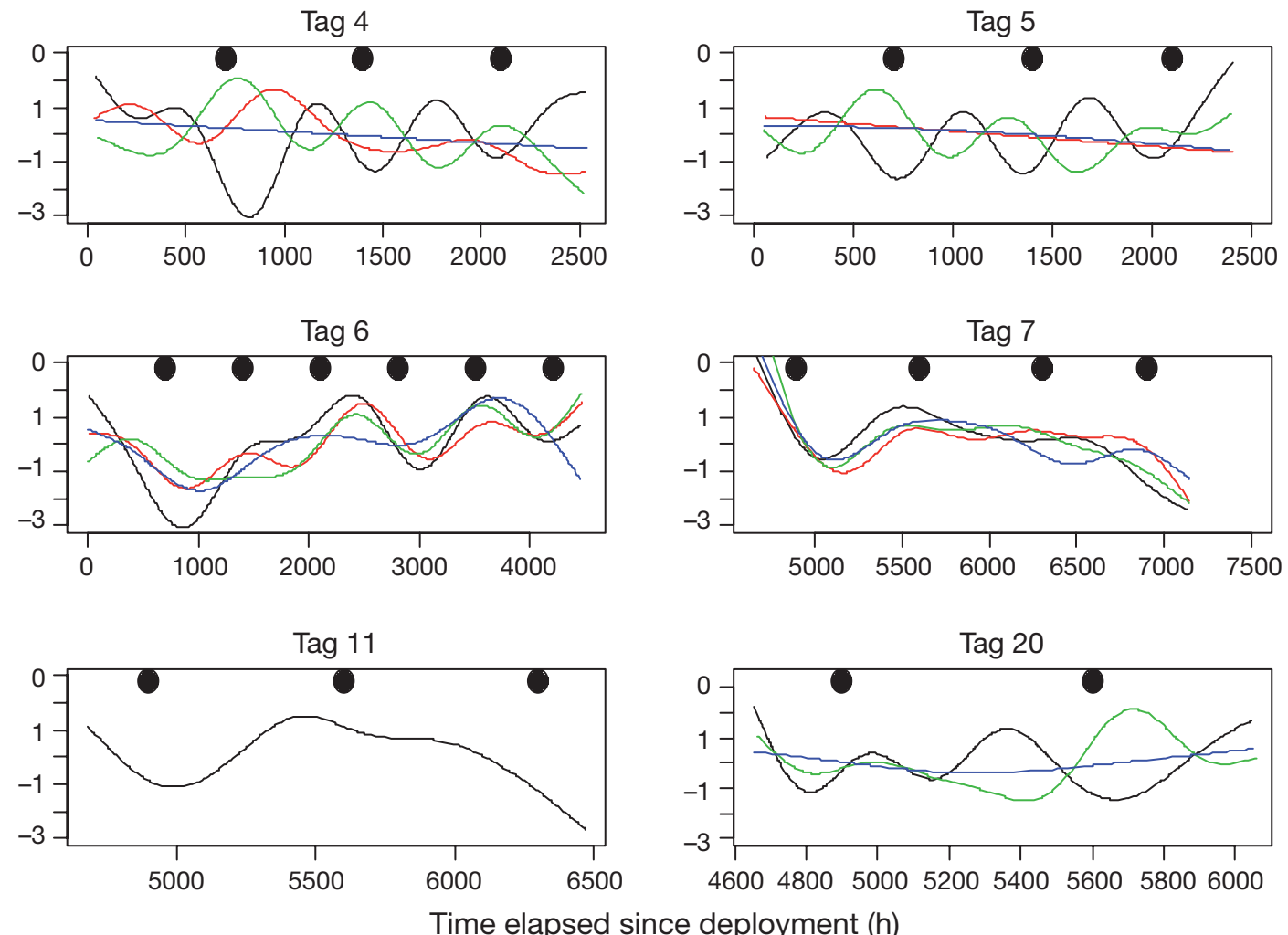

Fig. 3. Phoca vitulina. Smoothing functions describing the partial effect of 'hour' on the haul-out status of seals with Tags 4, 5, 6, 7, 11 and 20 over the entire tagging period in 4 tidal periods. For Tags 4, 5, 6 and 7 -black line: long-term smoother for the rising part of Tide 1; green line: rising part of Tide 2; red line: falling part of Tide 1; blue line: falling part of Tide 2; black dots: full moon. For Tags 11 and 20-black line: long-term smoother for the 4 tidal periods combined and for the rise and fall of Tidal Period 1, respectively; other lines as previously defined 


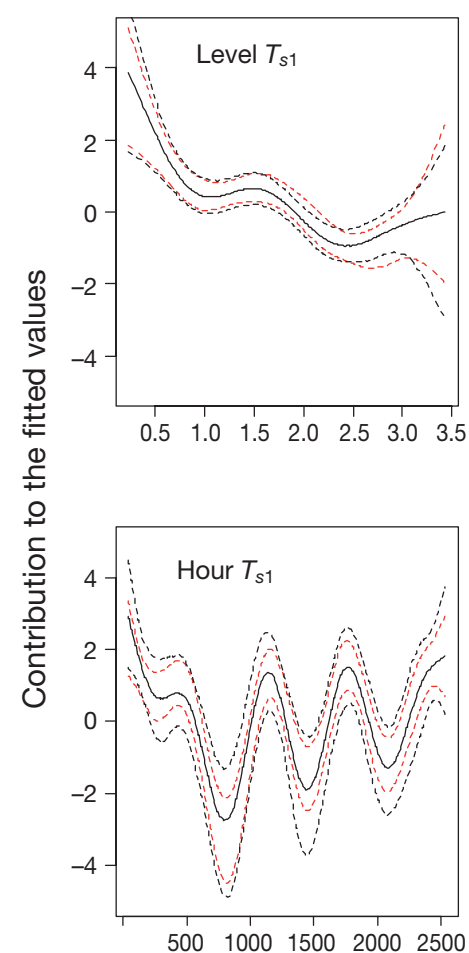

5001000150020002500
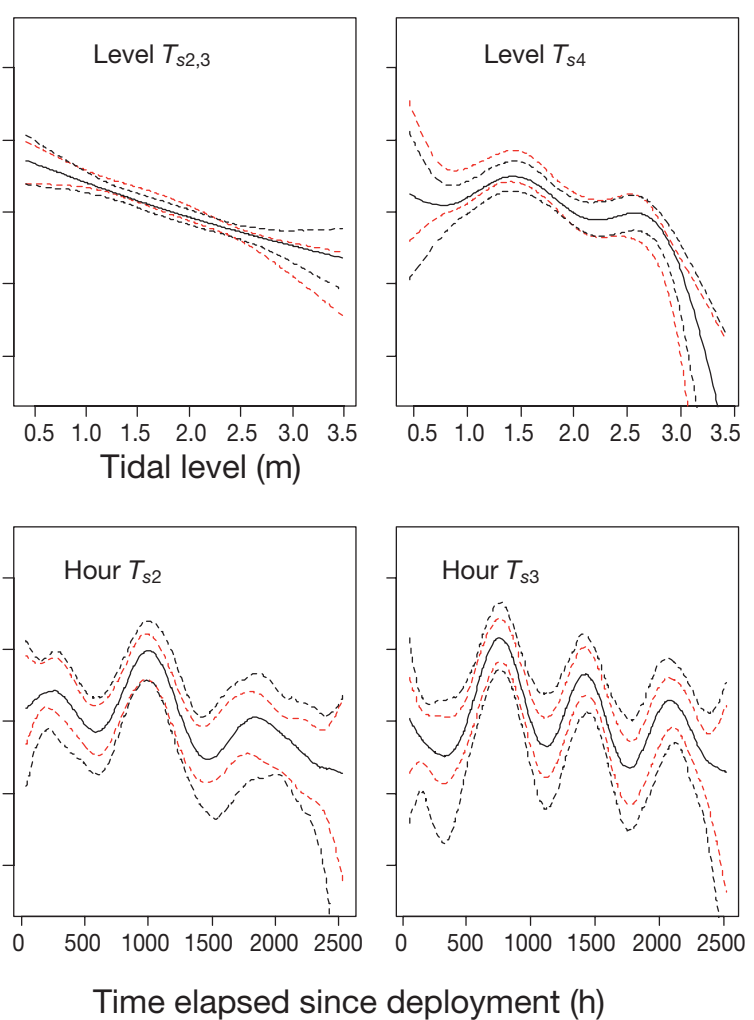

Time elapsed since deployment (h)
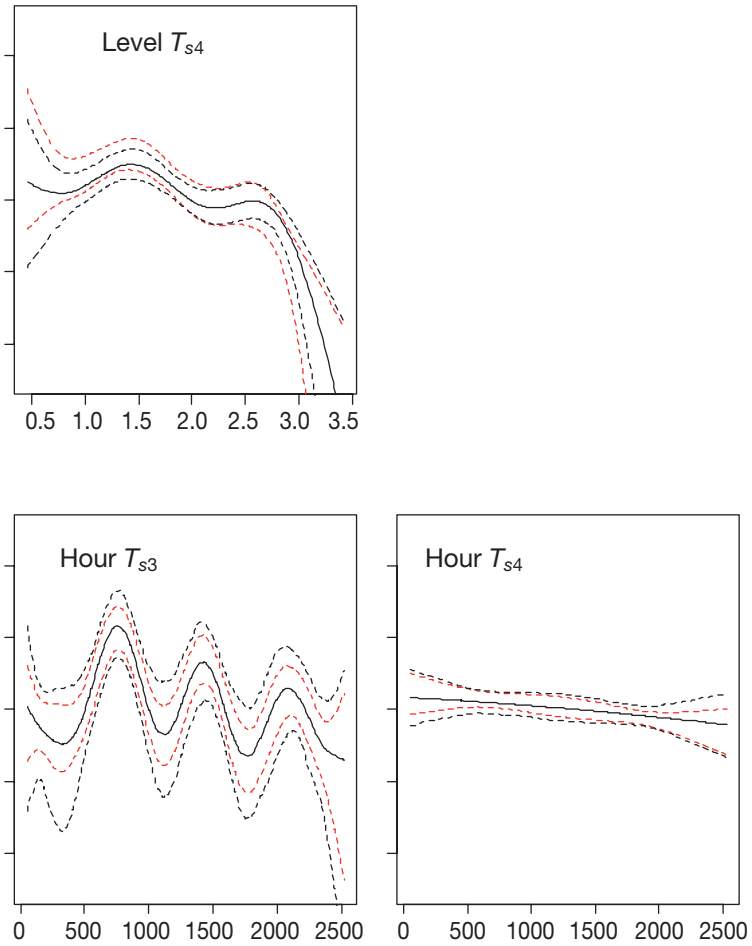

Fig. 4. Phoca vitulina. Smoothing functions with $95 \%$ confidence intervals obtained by the bootstrapping approach, describing the partial effects of 'hour' and 'tidal level' on the haul-out status of the seal with Tag 4 over the entire tagging period in the 4 tidal periods $\left(T_{s 1}\right.$ to $\left.T_{s 4}\right)$

tested for this effect (Table 3). The time of day had a significant effect on the short-term haul-out behaviour of all seals ( $p<0.001$ to $p<0.05)$ apart from Seals 4 and 7 . There were no obvious patterns in the auto-correlation function of the Pearson's residuals, indicating that the first-order auto regressive process structure in the GAMM dealt with the auto-correlation problem.

\section{DISCUSSION}

\section{Effects of time of day and tidal cycle on haul-out behaviour}

A significant tidal influence on the haul-out behaviour of tagged harbour seals Phoca vitulina was evident throughout the present study, with tagged seals hauled out more frequently at low tide. Haul-out sites in the study area are generally tidally influenced rocky skerries, with haul-out habitat submerged at high tide. Time of day had a significant influence on the haul-out behaviour of most tagged seals, although the daily haul-out pattern varied among individuals. A distinct diurnal pattern in haul-out behaviour was evident from 6 of the tagged seals, spending more time ashore during early to mid-afternoon. Overall, tagged seals spent more time ashore during the day than at night, possibly returning to the water to feed at night when foraging may be more profitable, as has been suggested for other species, e.g. fur seals Arctocephalus gazella (Croxall et al. 1985). Similar haul-out patterns have been observed in other studies of harbour seal haul-out behaviour (Boulva \& McLaren 1979, Thompson et al. 1989, Thompson \& Miller 1990, Watts 1993). The 2 seals that showed no distinct diurnal patterns in haul-out behaviour in the present study were the only adult males tagged prior to and during the breeding season. It is possible that these animals were breeding and spending more time in the water, increasing their chances of intercepting females (Van Parijs et al. 1997, 1999, 2000). As these animals were tagged in late April, it is not possible to say if this was a matingrelated shift in haul-out behaviour or whether these animals consistently displayed this haul-out behaviour.

\section{Seasonal changes in haul-out behaviour}

The haul-out behaviour of tagged seals in the present study varied over the tagging period, with maxi- 
Table 2. Phoca vitulina. Summary of optimum generalised additive models of haul-out status of tagged seals within the Kenmare River, Ireland; p-values represent bootstrapped probability values. Explanatory variables or smoothers, i.e. tidal level (level) and time elapsed since deployment (hour), were fitted as separate smoothers for 4 tidal periods ( $T_{s 1}$ to $\left.T_{s 4}\right)$ unless otherwise stated. The estimated degrees of freedom (edf) and degrees of freedom (df) are shown for variables fitted as smoothers and for parametric terms, respectively

\begin{tabular}{|c|c|c|c|c|c|c|c|}
\hline Smoother & & Tag 4 & Tag 5 & Tag 6 & Tag 7 & Tag 11 & Tag 20 \\
\hline Level $T_{s 1}$ & $\begin{array}{l}\text { edf } \\
\text { p-value }\end{array}$ & $\begin{array}{c}1.005 \\
<\mathbf{0 . 0 0 1}\end{array}$ & $\begin{array}{c}1.776 \\
<\mathbf{0 . 0 0 1}\end{array}$ & & $\begin{array}{c}1.887\left(T_{S 1-4}\right) \\
\quad<0.001\end{array}$ & $\begin{array}{c}2.596\left(T_{s 1-4}\right) \\
<\mathbf{0 . 0 0 1}\end{array}$ & $\begin{array}{l}1.001\left(T_{s 1-4}\right) \\
\quad<\mathbf{0 . 0 0 1}\end{array}$ \\
\hline Level $T_{s 2}$ & $\begin{array}{l}\text { edf } \\
\text { p-value }\end{array}$ & $\begin{array}{c}1.005\left(T_{s 2,3}\right) \\
<\mathbf{0 . 0 0 1}\end{array}$ & $\begin{array}{c}1.906 \\
<\mathbf{0 . 0 0 1}\end{array}$ & $\begin{array}{c}1.007 \\
<\mathbf{0 . 0 0 1}\end{array}$ & & & \\
\hline Level $T_{s 3}$ & $\begin{array}{l}\text { edf } \\
\text { p-value }\end{array}$ & & $\begin{array}{l}1.987 \\
<\mathbf{0 . 0 1}\end{array}$ & $\begin{array}{c}1.925 \\
<\mathbf{0 . 0 0 1}\end{array}$ & & & \\
\hline Level $T_{s 4}$ & $\begin{array}{l}\text { edf } \\
\text { p-value }\end{array}$ & $\begin{array}{c}4.405 \\
<\mathbf{0 . 0 0 1}\end{array}$ & $\begin{array}{c}3.024 \\
<0.001\end{array}$ & $\begin{array}{l}1.008 \\
<\mathbf{0 . 0 1}\end{array}$ & & & \\
\hline Hour $T_{s 1}$ & $\begin{array}{l}\text { edf } \\
p \text {-value }\end{array}$ & $\begin{array}{l}9.000 \\
<\mathbf{0 . 0 5}\end{array}$ & $\begin{array}{l}8.625 \\
<\mathbf{0 . 0 5}\end{array}$ & $\begin{array}{c}8.939 \\
<\mathbf{0 . 0 0 1}\end{array}$ & $\begin{array}{c}7.193 \\
=0.890\end{array}$ & $\begin{array}{c}5.787\left(T_{s 1-4}\right) \\
\quad<\mathbf{0 . 0 5}\end{array}$ & $\begin{array}{l}8.681\left(T_{s 1,2}\right) \\
\quad<\mathbf{0 . 0 5}\end{array}$ \\
\hline Hour $T_{s 2}$ & $\begin{array}{l}\text { edf } \\
p \text {-value }\end{array}$ & $\begin{array}{c}7.638 \\
=0.064\end{array}$ & $\begin{array}{c}1.000 \\
=0.871\end{array}$ & $\begin{array}{l}8.822 \\
<\mathbf{0 . 0 5}\end{array}$ & $\begin{array}{c}8.205 \\
=0.525\end{array}$ & & \\
\hline Hour $T_{s 3}$ & $\begin{array}{l}\text { edf } \\
\text { p-value }\end{array}$ & $\begin{array}{l}9.000 \\
<\mathbf{0 . 0 5}\end{array}$ & $\begin{array}{c}8.481 \\
=0.286\end{array}$ & $\begin{array}{l}8.866 \\
=0.158\end{array}$ & $\begin{array}{c}6.787 \\
=0.811\end{array}$ & & $\begin{array}{l}7.200 \\
<\mathbf{0 . 0 5}\end{array}$ \\
\hline Hour $T_{s 4}$ & $\begin{array}{l}\text { edf } \\
\text { p-value }\end{array}$ & $\begin{array}{c}1.001 \\
=0.246\end{array}$ & $\begin{array}{c}1.508 \\
=0.874\end{array}$ & $\begin{array}{l}7.229 \\
<\mathbf{0 . 0 5}\end{array}$ & $\begin{array}{c}0.991 \\
=0.633\end{array}$ & & $\begin{array}{c}1.909 \\
=0.111\end{array}$ \\
\hline Month & $\begin{array}{l}\text { df } \\
\text { p-value }\end{array}$ & & $\begin{aligned} & 4.000 \\
= & 0.741\end{aligned}$ & $\begin{array}{l}6.000 \\
<\mathbf{0 . 0 5}\end{array}$ & $\begin{array}{c}4.000 \\
=0.890\end{array}$ & $\begin{array}{c}3.000 \\
=0.063\end{array}$ & $\begin{array}{c}4.000 \\
=0.429\end{array}$ \\
\hline $\begin{array}{l}\text { Cosine: } \\
\text { Time of day }\end{array}$ & $\begin{array}{l}\mathrm{df} \\
\mathrm{p} \text {-value }\end{array}$ & $\begin{array}{c}1.000 \\
=0.232\end{array}$ & $\begin{array}{c}1.000 \\
<\mathbf{0 . 0 0 1}\end{array}$ & $\begin{array}{c}1.000 \\
<0.001\end{array}$ & $\begin{array}{c}1.843 \\
=0.117\end{array}$ & $\begin{array}{c}1.000 \\
<\mathbf{0 . 0 0 1}\end{array}$ & $\begin{array}{c}1.000 \\
<\mathbf{0 . 0 0 1}\end{array}$ \\
\hline $\begin{array}{l}\text { Sine: } \\
\text { Time of day }\end{array}$ & $\begin{array}{l}\text { df } \\
\text { p-value }\end{array}$ & $\begin{array}{c}1.000 \\
=0.511\end{array}$ & $\begin{array}{c}1.000 \\
=0.729\end{array}$ & $\begin{array}{c}1.000 \\
=0.358\end{array}$ & $\begin{array}{c}1.000 \\
=0.164\end{array}$ & $\begin{array}{c}1.000 \\
=0.251\end{array}$ & $\begin{array}{c}1.000 \\
<\mathbf{0 . 0 0 1}\end{array}$ \\
\hline
\end{tabular}

mum time spent ashore post-moult in October, decreasing over the winter months to a minimum in February. Changes in the haul-out behaviour of the tagged seals are reflected in the seasonal change in abundance of seals at haul-out sites in the study area (M. Cronin, Coastal \& Marine Resources Centre, unpubl. data). Absence from the haul-out sites during winter may suggest an increase in foraging effort or relocation to more offshore foraging areas, corresponding to longer at-sea durations. Previous studies have shown that body condition in harbour seals is highest in winter (Drescher 1979, Pitcher 1986). Winter activity patterns of harbour seals tagged in Scotland and Alaska suggest that they spend less time in inshore waters at this time of the year (Thompson et al. 1989, Rehberg \& Small 2001, Sharples 2005).

\section{Potential lunar pattern in haul-out behaviour}

There were cyclic patterns apparent in the haul-out behaviour of the seals tagged over the autumn/winter period and a potential lunar influence on the seals' activity. This was shown by a predilection of going to sea just after the full moon each month. Predators at higher trophic levels may modify their behaviour to optimize the exploitation of vertically migrating prey (Hays 2003), indeed nocturnal feeding has been reported in harbour seals and it has been suggested that seals feed nocturnally in response to changes in the vertical distribution or schooling behaviour of their prey (Croxall et al. 1985, Thompson et al. 1989). The possible lunar

Table 3. Phoca vitulina. Summary of optimum generalised additive mixed models to describe the haul-out status of seals with shorter time series that were tagged within the Kenmare River, Ireland. Probability values, estimated degrees of freedoms (edf) for smoothers and degrees of freedom (df) for nominal variables and $\phi$-values are given; the $\phi$ values denote the correlation between sequential hours

\begin{tabular}{|llrrrr|}
\hline Explanatory variable & & Tag 2 & Tag 3 & Tag 9 & Tag 10 \\
\hline Level & edf & 1.000 & 1.000 & 1.000 & 2.689 \\
& p-value & $\mathbf{< . 0 0 1}$ & $\mathbf{< 0 . 0 1}$ & $<\mathbf{0 . 0 0 1}$ & $<\mathbf{0 . 0 0 1}$ \\
Cosine: Time of day & df & 1.000 & 1.000 & 1.000 & 1.000 \\
& p-value & $<\mathbf{0 . 0 5}$ & $<\mathbf{0 . 0 0 1}$ & $<\mathbf{0 . 0 1}$ & $<\mathbf{0 . 0 0 1}$ \\
Sine: Time of day & df & 1.000 & 1.000 & 1.000 & 1.000 \\
& p-value & $<\mathbf{0 . 0 5}$ & $=0.233$ & $=0.617$ & $<\mathbf{0 . 0 5}$ \\
Phi $(\phi)$ value & & 0.7519 & 0.5809 & 0.6438 & 0.7488 \\
\hline
\end{tabular}


cycle in the behaviour of the seals tagged post-moult observed in the present study may be linked to a lunar periodicity in the food chain; fish abundance in surface layers may increase responding to enhanced foraging opportunities of zooplankton near the surface as a result of the light from the moon. Local increases in food availability on the incoming tide may explain the predilection shown by some of the tagged seals to go to sea on the first rising tide following a full moon.

It would be interesting to extend the model in Eq. (3) to:

$\operatorname{Logit}\left(p_{s}\right)=$ intercept $+\mathrm{f}($ tide $): T_{s}+$ function(time of day) $+\mathrm{f}($ hour $): T_{s}+$ month $_{s}+$ function(full moon $\left._{s}\right)$

The expression function(full moon $_{s}$ ) models the effect of full moon on hauling out probabilities. One option is to define a new covariate as 'number of days since, or to, the nearest full moon'. Alternatively, we can use 'number of hours since, or to, the nearest full moon'. This covariate can then be used as a parametric covariate, or even as a smoother. The problem is that number of days to full moon will be collinear with hours, as, for most seals, the length of the time series only covers 3 or 4 full moons. Hence, all that we can do for the moment is to plot the long-term trends and superimpose the full moon on it, and wait until longer time series become available.

The haul-out behaviour of the adult seals tagged in the latter part of the tagging period, i.e. during the spring and early summer, do not show the clear cyclic patterns in behaviour shown by seals tagged in autumn. The juvenile female, however, showed a cyclic pattern in haul-out activity from mid-May to mid-June, when the tag stopped transmitting. The patterns observed may be due to changes in their haul-out behaviour associated with breeding season. Male adult harbour seals have been shown to spend more time at sea during summer (Härkönen et al. 1999) and to restrict their range to areas where they are most likely to intercept females (Van Parijs et al. 1997, 1999, 2000, Reder et al. 2003). It is suggested that in the months following the annual moult, harbour seal haulout behaviour may be predominantly influenced by foraging activity and/or foraging location and that this foraging activity could be influenced by lunar cycles. Later in the annual cycle, haul-out patterns are influenced more by breeding-related behaviour, possibly explaining the observed differences in the potential influence of the lunar cycle on behaviour.

A possible lunar influence on the hauling-out behaviour of the Pacific harbour seal Phoca vitulina richardii has been reported by Watts (1993) based on changes in attendance of seals at haul-out sites and by Simpkins et al. (2003) using telemetry and statistical modelling that identified a periodicity in haul-out behaviour coin- ciding with the lunar tidal cycle. The haul-out data modelled were from the period of mid-August to midSeptember only, so a monthly cyclic pattern, if present, was not identified. The present study is the first to establish possible lunar patterns in the haul-out behaviour of individual seals and to identify individual differences in behavioural patterns between tidal periods; the advances in statistical modelling techniques have enabled us to identify such details. Differentiating between tidal periods accounted for the fact that a particular tidal level will differ between periods, presenting different environmental and ecological parameters, such as current speed and direction, daylight and food availability.

We suggest that the potential lunar effect on the haul-out behaviour of seals observed in the present study warrants further investigation. Modelling data on the haul-out behaviour of harbour seals has primarily been carried out to correct count data and has, thus, focused on discrete periods of time during the seals' annual cycle. The approach described in the present study could be used on existing and future data on the haul-out behaviour of individual harbour seals across their geographical range, in order to determine if the patterns in behaviour observed in the present study are common phenomena and to identify any potential demographical or geographical variation.

\section{Population assessment/conservation implications}

The data resulting from the present study show large variations in the haul-out behaviour between individual seals. Moreover, this study is the first to demonstrate variability in the haul-out behaviour of harbour seals between different tidal periods. This has implications for using information on the behaviour of tagged individuals to derive correction factors for count data and, therefore, has important implications for population assessment for conservation purposes across the species' entire geographical range. The proportion of tagged seals hauled out during actual counts or during 'ideal conditions' has been used to derive correction factors for count data (Thompson et al. 1997, Huber et al. 2001, Simpkins et al. 2003). Another means of deriving correction factors is to model telemetry-derived haul-out data and determine the probability of haulout under survey conditions. However, identifying an optimal model for the haul-out behaviour of a small sample of tagged seals as a function of covariates, using mixed modelling techniques and treating tag as a random factor, is only applicable if all seals behave with random variations around the main pattern. Thompson et al. (1998) showed that the proportion of time spent at sea, trip duration and foraging range of 
harbour seals were all positively related to body size and suggest that both environmental and endogenous factors shape the foraging characteristics of individuals. If the reason for the variation in haul-out behaviour between individuals were established (e.g. demographical, seasonal and/or geographical), this could be accounted for in a random effects model, and haul-out probabilities under 'ideal' conditions or during surveys could be estimated, providing a means for correcting count data. Increasing the sample size of tagged seals, with a more balanced age and sex ratio, targeting a more diverse range of haul-out sites and including as many covariates as possible, such as age and sex, in the analysis would help achieve this.

Overall, the present study provided information, heretofore unavailable, on the haul-out behaviour of harbour seals on Irish shores and an understanding of the factors influencing this behaviour that can be taken into account during the planning of subsequent population assessment surveys. The detailed analysis of the haul-out dataset was possible with the application of advanced statistical modelling techniques and identified some interesting patterns in the seals' behaviour that warrant further investigation. Moreover, they indicate that caution should be taken in using correction factors based on the behaviour of a small number of individuals, as has previously been done. The statistical approach described could be applied to similar data from other aquatic vertebrates. The technology employed to gather the haul-out data had not been used in this context prior to our study and proved to be an effective tool for acquiring this hard-to-get data. With the ever-expanding global GSM network coverage, the system has significant potential applications in behavioural studies on other protected or endangered vertebrates.

Acknowledgements. The study was partly funded by the Higher Education Authority, Ireland, and by the National Parks and Wildlife Service of the Department of Environment, Heritage and Local Government. Many thanks to the following, who assisted in the field with seal captures: Mick Mackey, Simon Ingram, Daphne Roycroft, Allen Whittaker, Oliver Ó Cadhla, Alisa Hall, Declan O'Donnell and Clare Heardman.

\section{LITERATURE CITED}

Adkison MD, Quinn TJ, Small RJ (2003) Evaluation of the Alaska harbour seal (Phoca vitulina) population survey: a simulation study. Mar Mamm Sci 19:764-790

Bigg MA (1981). Harbour seal Phoca vitulina Linnaeus, 1758, and Phoca largha, Pallas, 1811. In: Ridgeway H, Harrison RJ (eds) Handbook of marine mammals. Academic Press, London, p 1-77

Boulva J, McLaren IA (1979) Biology of the harbour seal Phoca vitulina in eastern Canada. Bull Fish Res Board Can 200:1-24
Boveng PL, Bengston JL, Withrow DE, Cesarone JC, Simpkins MA, Frost KJ, Burns JJ (2003) The abundance of harbor seals in the Gulf of Alaska. Mar Mamm Sci 19:111-127

Cronin MA (2007) The abundance, habitat use and haul-out behaviour of the harbour seal (Phoca vitulina vitulina) in southwest Ireland. PhD thesis, University College Cork, Cork

Cronin MA, McConnell BJ (2008) SMS seal: a new technique to measure haul-out behaviour in marine vertebrates. J Exp Mar Biol Ecol 362:43-48

Cronin M, Duck C, O' Cadhla O, Nairn R, Strong D, O' Keeffe C (2007) An assessment of population size and distribution of harbour seals (Phoca vitulina vitulina) in the Republic of Ireland during the moult season in August 2003. J Zool (Lond) 273:131-139

- Croxall JP, Everson I, Kooyman GL, Ricketts C, Davis RW (1985) Fur seal diving behaviour in relation to vertical distribution of krill. J Anim Ecol 54:1-8

Cuthill I (1991) Field experiments in animal behaviour: methods and ethics. Anim Behav 42:1007-1014

Davidson AC, Hinkley DV (1997) Bootstrap methods and their applications. Cambridge University Press, Cambridge

Drescher HE (1979) Biology, ecology and conservation of harbour seals in the tidelines of Schleswig-Holstein. Beitr Wildbiol 1:1-73

Fedak MA, Anderson SS, Curry MG (1983) Attachment of a radio tag to the fur of seals. J Zool 200:298-300

Findley DF, Monsell BC, Bell WR, Otto MC, Chen BC (1998) New capabilities and methods of the X-12-ARIMA seasonal adjustment program. J Bus Econ Stat 16:127-176

Frost KJ, Lowry LF, Ver Hoef JM (1999) Monitoring the trend of harbour seals in Prince William Sound, Alaska after the Exxon Valdez oil spill. Mar Mamm Sci 15:494-506

Grellier K, Thompson PM, Corpe HM (1996) The effect of weather conditions on harbor seal (Phoca vitulina) haulout behaviour in the Moray Firth, northeast Scotland. Can J Zool 74:1806-1811

Härkönen T, Heide-Jorgensen MP (1990) Comparative life histories of East Atlantic and other harbour seal populations. Ophelia 32:211-235

> Härkönen TK, Harding C, Lunneryd SG (1999) Age and sex specific behaviour in harbour seals Phoca vitulina leads to biased estimates of vital population parameters. J Appl Ecol 36:825-841

Harvey AC (1989) Forecasting, structural time series models and the Kalman filter. Cambridge University Press, Cambridge

> Hays GC (2003) A review of the adaptive significance and ecosystem consequences of zooplankton diel vertical migrations. Hydrobiologia 503:163-170

Huber HR, Jeffries SJ, Brown RF, Delong R, Vanblaricom G (2001) Correcting aerial survey counts of harbor seals (Phoca vitulina richardi) in Washington and Oregon. Mar Mamm Sci 17:276-293

Jeffries SJ (1993) Techniques for capturing, handling and marking harbour seals. Aquat Mamm 19:21-25

Lydersen C, Kovacs KM (2005) Growth and population parameters of the world's northernmost harbour seals Phoca vitulina residing in Svalbard, Norway. Pol Biol 28(2): 156-163

Makridakis S, Wheelwright S, Hyndman R (1998) Forecasting: methods and applications, 3rd edn. Wiley, New York

McConnell BJ, Beaton R, Bryant E, Hunter C, Lovell P, Hall A (2004) Phoning home-a new GSM mobile phone telemetry system to collect mark-recapture data. Mar Mamm Sci 20:274-283

Ostrom CW (1990) Time series analysis: regression techniques, 2nd edn. Sage Publications, Beverly Hills, CA 
Pitcher KW (1986) Variation in blubber thickness of harbour seals in southern Alaska. J Wildl Manag 50:463-466

Reder S, Lydersen C, Arnold W, Kovacs K (2003) Haul-out behaviour of high Arctic harbour seals (Phoca vitulina vitulina) in Svalbard, Norway. Polar Biol 27:6-16

Rehberg MJ, Small RJ (2001) Dive behaviour, haul-out patterns and movements of harbour seal pups in the Kodiak archipelago, 1997-2000. In: Harbor seal investigations in Alaska. Alaska Department of Fish \& Game, Division of Wildlife Conservation, Anchorage, AK, p 209-238

Ries EH, Hiby LR, Reijnders PJH (1998) Maximum likelihood population size estimation of harbour seals in the Dutch Wadden Sea based on a mark-recapture experiment. J Appl Ecol 35:332-339

Sharples RJ (2005) Ecology of harbour seals in southeastern Scotland. PhD thesis, University of St. Andrews, Fife

Simpkins MA, Withrow DE, Cesarone JC, Boveng PL (2003) Stability in the proportion of harbor seals hauled out under locally ideal conditions. Mar Mamm Sci 19:791-805

Small RJ, Pendleton GW, Pitcher KW (2003) Trends in abundance of Alaska harbor seals, 1983-2001. Mar Mamm Sci 19:344-362

Stewart BS (1984) Diurnal patterns of harbour seals at San Miguel Island, California. J Wildl Manag 48:1459-1461

Thompson PM, Harwood J (1990) Methods for estimating the population size of common seals Phoca vitulina. J Appl Ecol 27:924-938

Thompson PM, Miller D (1990) Summer foraging activity and movements of radio-tagged common seals (Phoca vitulina) in the Moray Firth, Scotland. J Appl Ecol 27:492-501

Thompson PM, Fedak M, McConnell B, Nicholas KS (1989) Seasonal and sex-related variation in the activity patterns of common seals (Phoca vitulina). J Appl Ecol 26:521-535

Thompson PM, Miller D, Cooper R, Hammond PS (1994) Changes in the distribution and activity of female harbour seals during the breeding season: implications for their

Editorial responsibility: Rory Wilson,

Swansea, UK lactation strategy and mating patterns. J Anim Ecol 63: $24-30$

Thompson PM, Tollit DJ, Wood D, Corpe HM, Hammond PS, Mackay A (1997) Estimating harbour seal abundance and status in an estuarine habitat in north-east Scotland. J Appl Ecol 34:43-52

> Thompson PM, Mackay A, Tollit DJ, Enderby S, Hammond PS (1998) The influence of body size and sex on the characteristics of harbour seal foraging trips. Can J Zool 76: 1044-1053

> Van Parijs SM, Thompson PM, Tollit DJ, Mackay A (1997) Distribution and activity of male harbour seals during the mating season. Anim Behav 54:35-43

> Van Parijs SM, Hastie GD, Thompson PM (1999) Geographic variation in temporal and spatial patterns of aquatic mating male harbour seals. Anim Behav 58:1231-1239

Van Parijs SM, Hastie GD, Thompson PM (2000) Individual and geographical variation in display behaviour of male harbor seals in Scotland. Anim Behav 59:559-568

> Watts P (1993) Possible lunar influence on hauling-out behaviour by the Pacific harbour seal (Phoca vitulina richardi). Mar Mamm Sci 9:68-76

Wilson RP, Grant WS, Duffy DC (1986) Recording devices on free-ranging marine animals: Does measurement affect foraging performance? Ecology 67:1091-1093

Wood SN (2006) mgcv 1.3, R package. Available at http:// cran.r-project.org

Yochem PK, Stewart BS, Delong RL, DeMaster DP (1987) Diel haul-out patterns and site fidelity of harbour seals (Phoca vitulina richardi) on San Miguel Island, California in autumn. Mar Mamm Sci 3:323-332

Zuur AF, Ieno EN, Smith GM (2007) Analysing ecological data. Springer-Verlag, New York

Zuur AF, Ieno EN, Walker N, Saveliev AA, Smith GM (2008) Mixed effects models and extensions in ecology with $\mathrm{R}$. Springer-Verlag, New York

Submitted: June 3, 2008; Accepted: October 30, 2008

Proofs received from author(s): February 17, 2009 